\title{
Cambio agrario y poblamiento regional en Chile
}

\author{
Alejandro Canales Cerón*
}

En este artículo se presenta un análisis sobre el impacto del cambio agrario en la dinámica del poblamiento regional en Chile en los últimos 35 años. Las transformaciones en la estructura agraria han generado importantes cambios en la configuración espacial de las relaciones campo-ciudad, en particular a partir del nuevo carácter de la migración rural-urbana en contextos regionales. Si hasta los años sesenta la migración del campo a la ciudad estuvo asociada a una movilidad ocupacional -de empleos agricolas a empleos urbanos-, a partir de los setenta, en cambio, esta relación prácticamente desaparece presentándose una virtual disociación entre la movilidad territorial de la población y la movilidad ocupacional de la fuerza de trabajo. Esta disociación constitu ye un componente central en la actual configuración regional de las relaciones campo ciudad.

\section{Introducción}

A partir del golpe militar, se implantó en Chile un nuevo patrón de desarrollo económico y de organización social y política del país que ha incidido de manera importante en la dinámica del poblamiento y la movilidad espacial de la población tanto nacional como regionalmente. Uno de los pilares de este nuevo proyecto, iniciado por los militares y continuado por los gobiernos civiles, corresponde al proceso de modernización de la estructura agraria, que ha derivado en una reformulación radical de las relaciones campo-ciudad en los ámbitos nacional y regional, y en el que la movilidad de la población ha adquirido un significado de particular importancia. ${ }^{1}$

A diferencia de similares procesos de modernización agrícola impulsados en otros países de América Latina en la década de los setenta, el caso de Chile se trata no sólo de una reconversión agroproductiva, sino también de una virtual refundación social, política y económica de la estructura agraria y la sociedad rural. En efecto, el proyecto agrario de los militares impulsado durante la segunda mitad de los setenta, no implicó un virtual retorno al sistema de hacienda prevaleciente hasta antes de la Reforma Agraria a inicios de los sesenta, sino que, por el contrario, profundizó las transformaciones estructurales

* El Colegio de la Frontera Norte.

${ }^{1}$ Sobre la modernización del agro chileno, véase Ortega, 1987; Gómez y E que, 1988 
iniciadas en ese periodo, pero reorientándolas hacia una refundación capitalista en términos del sistema de propiedad, con la liberación del mercado de tierras, la desregulación del mercado laboral, y la proletarización de la fuerza de trabajo, entre otros aspectos. ${ }^{2}$

Junto a esta modernización del agro chileno, el modelo económico impulsado por el gobierno militar implicó una profunda reconversión productiva y una restructuración territorial de la economía nacional, ${ }^{3}$ lo que tendió a revertir el anterior desarrollo urbano-industrial, a la vez que fomentó el desarrollo agrorregional con base en un modelo agroexportador y la consolidación de formas capitalistas de producción en el agro que sustituyeron tanto a las heredadas de la reforma agraria, como a los resabios del sistema de hacienda que aún persistían.

En este contexto, la dinámica del cambio agrario en Chile parece tener un papel fundamental en la reestructuración del poblamiento en el ámbito nacional y en el regional. Si hasta principios de los setenta la relación entre estilo de desarrollo y sistema de poblamiento, aparecía mediada por la particular forma de organización espacial de las relaciones campo-ciudad, impuestas por el proceso de urbanización e industrialización de la economía chilena (Filippo y Bravo, 1977; Geisse, 1983), en los ochenta en cambio, tal papel corresponde a la reconversión productiva del agro y a la modernización de sus estructuras sociales y económicas. En particular su movilidad y asentamiento en espacios regionales.

Con base en lo anterior, en este trabajo presentamos un análisis sobre las diferentes formas en que la estructura agraria ha incidido e incide actualmente en el proceso de poblamiento y redistribución espacial de la población, nacional y regionalmente. El énfasis es puesto en la dinámica del empleo agrícola y las características socioespàciales del proceso de reproducción de la fuerza de trabajo. Nuestra tesis se refiere a que las transformaciones en la estructura agraria (su refundación económica, social y política) parece sustentarse en una creciente disociación entre los espacios y los tiempos del proceso de trabajo agrícola, y los de la reproducción de la fuerza de trabajo, disociación que por lo mismo constituye un componente central en la configuración de una nueva ruralidad; esto es, de nuevas pautas de

${ }^{2}$ Sobre el carácter fundacional del proyecto económico y social de los militares, véase Garretón, 1983; y sobre el modelo agrario, Crispi, 1980.

${ }^{3}$ Sobre los impactos a nivel regional del modelo neoliberal, véase Boisier, 1990. 
constitución de lo rural (y por ende, de lo urbano) especialmente en ámbitos regionales. ${ }^{4}$

El análisis lo ilustraremos con datos empíricos para el periodo 1960-1982, ${ }^{5}$ y referidos a la VI Región, del Libertador Bernardo O'Higgins, en donde los procesos de cambio de la estructura agraria y en las pautas del poblamien to regional, han sido más profundos que en las demás regiones del país.

\section{Empleo agrícola y poblamiento rural en la VI Región}

\section{Características generales y crecimiento demográfico}

La VI Región, del Libertador Bernardo O'Higgins, se ubica inmediatamente al sur de la Región Metropolitana (ex provincia de Santiago), y está conformada por las provincias de Cachapoal (exprovincia de O'Higgins), la de Colchagua y la de Cardenal Caro. En conjunto, las tres abarcan una superficie de $16366 \mathrm{~km}^{2}$, que corresponden a $2.2 \%$ de la superficie continental del país, proporción que ubica a la región junto a la $\mathrm{V}$, de Valparaíso, como una de las más pequeñas del país (mapa 1). No obstante, en esta región se asienta más de $5 \%$ de la población del país, convirtiéndola en una de las regiones más densamente pobladas con un promedio de 42.1 habitantes $/ \mathrm{km}^{2}$ en 1992 , cifra superada solamente por la Región Metropolitana (Santiago, la capital del país) y las regiones V (Valparaíso) y VIII (Concepción), que constituyen las áreas de mayor concentración demográfica, económica y política.

En cuanto a la dinámica de crecimiento demográfico y sus componen tes en la región, en el cuadro 1 se ilustran algunos datos para el periodo $1960-1980 .{ }^{6}$ De una década a otra, observamos un significati-

${ }^{4} \mathrm{Al}$ final de este trabajo presentamos una reflexión sobre el sentido de esta disociación, así como del significado de esta nueva ruralidad.

5 Sobre el censo de 1992 aún no se dispone de tabulados con el suficiente nivel de desagregación que se requiere para sustentar el análisis que se presenta.

${ }^{6}$ Para la estimación de los componentes del crecimiento demográfico, se utilizaron distintas técnicas demográficas. A partir de datos de paridez media y con base en métodos P/F, se hicieron estimaciones de los niveles de fecundidad. Por su parte, usando el modelo chileno de Celade se construyeron tablas de vida para ambos sexos, y con base en ellas se estimaron los niveles de mortalidad. Finalmente, por medio de métodos indirectos se estimaron los saldos netos migratorios. Para más detalles, véase Alejandro Canales, 1995. 


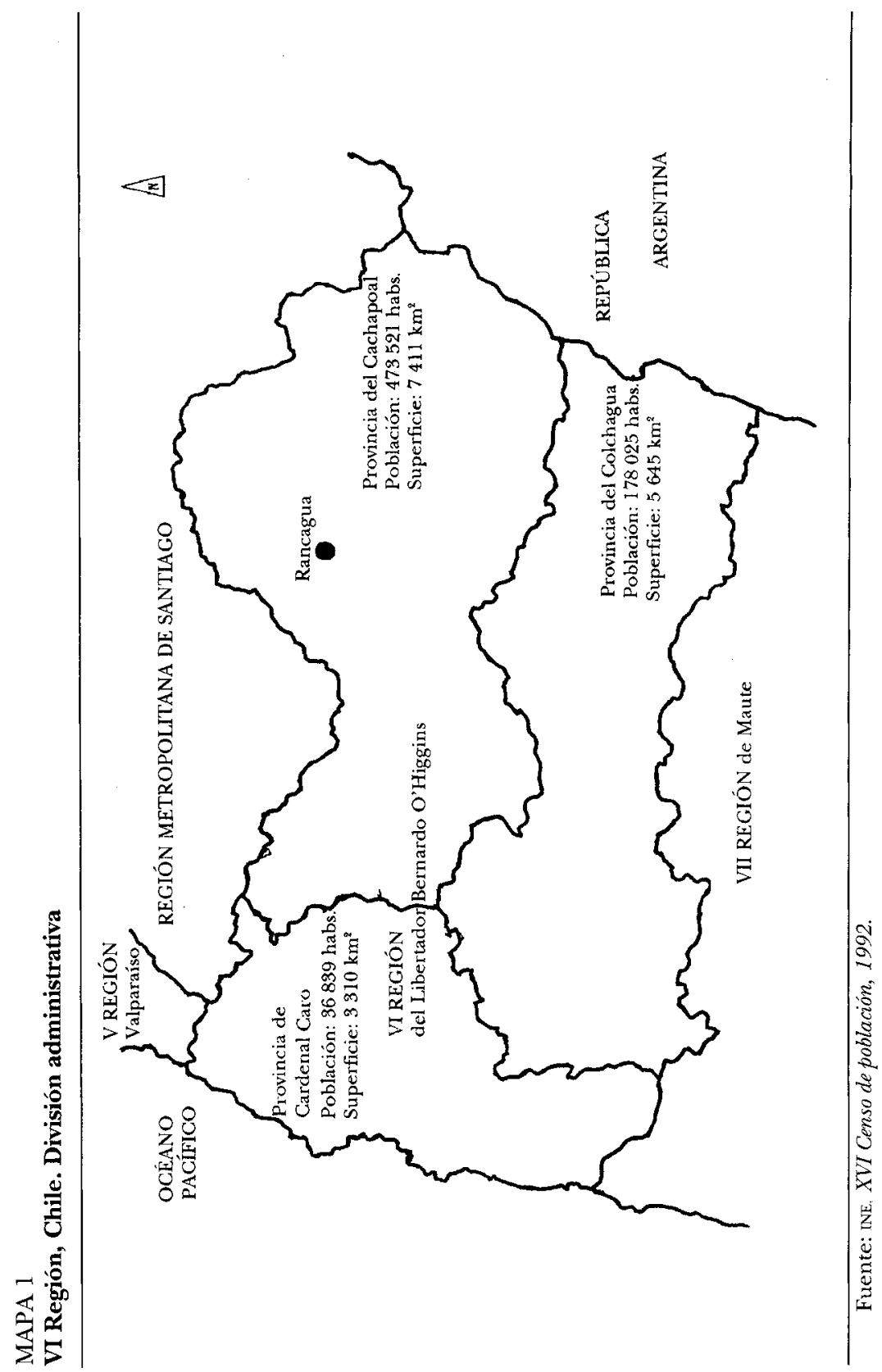


vo incremento en el ritmo de crecimiento demográfico de la VI Región. De un nivel de $1.1 \%$ en los sesenta, se eleva a $1.8 \%$ una década después. Este incremento se sustenta en un menor nivel de la emigración neta de la región, la que se reduce del nivel de $1.4 \%$ en los sesenta a sólo $0.2 \%$ en los setenta. Esta mayor capacidad de retención/atracción de población, permite incluso revertir el efecto negativo que sobre el crecimiento de la población tuviera el descenso de la tasa de crecimiento natural (cuadro 1).

\section{CUADRO 1}

VI Región, Chile. Componentes del crecimiento demográfico, 1960-1970 y 1970-1980

\begin{tabular}{lcc}
\hline Componente del crecimiento & $1960-1970$ & $1970-1980$ \\
\hline Grecimiento total & 1.13 & 1.79 \\
Grecimiento natural & 2.51 & 2.01 \\
Tasa de natalidad & 3.61 & 2.84 \\
Tasa de mortalidad & 1.10 & 0.83 \\
Migración neta & -1.38 & -0.22 \\
\hline
\end{tabular}

Fuente: Canales, 1995: 247, cuadro VI.12.

\section{Redistribución espacial de la población}

De 1960 a 1970 se observa un importante descenso de la población rural dispersa (en localidades con menos de 300 habitantes), así como la residente en poblados pequeños (de menos de 5000 habitantes). Paralelamente se incrementa la participación de la población residente en las dos principales ciudades de la región, Rancagua y San Fernando (gráfica 1). Esto marca una pauta específica de movilidad intrarregional de la población, que se caracteriza por la emigración rural y la inmigración urbana, reproduciendo en este nivel, las tendencias que se observan nacionalmente.

No obstante, en los setenta se detectan importantes cambios en este patrón de movilidad intrarregional. Por un lado, la población en localidades dispersas se reduce sustancialmente, representando en 1982 sólo $19.3 \%$ de la población total. Asimismo, las localidades de 300 a 4999 habitantes son las que muestran el mayor incremento, al crecer de $25.7 \%$ en 1970 a $38 \%$ en 1982 , constituyendo así el princi- 


\section{GRÁFICA 1}

\section{Región, Chile. Población por tamaño de localidad}

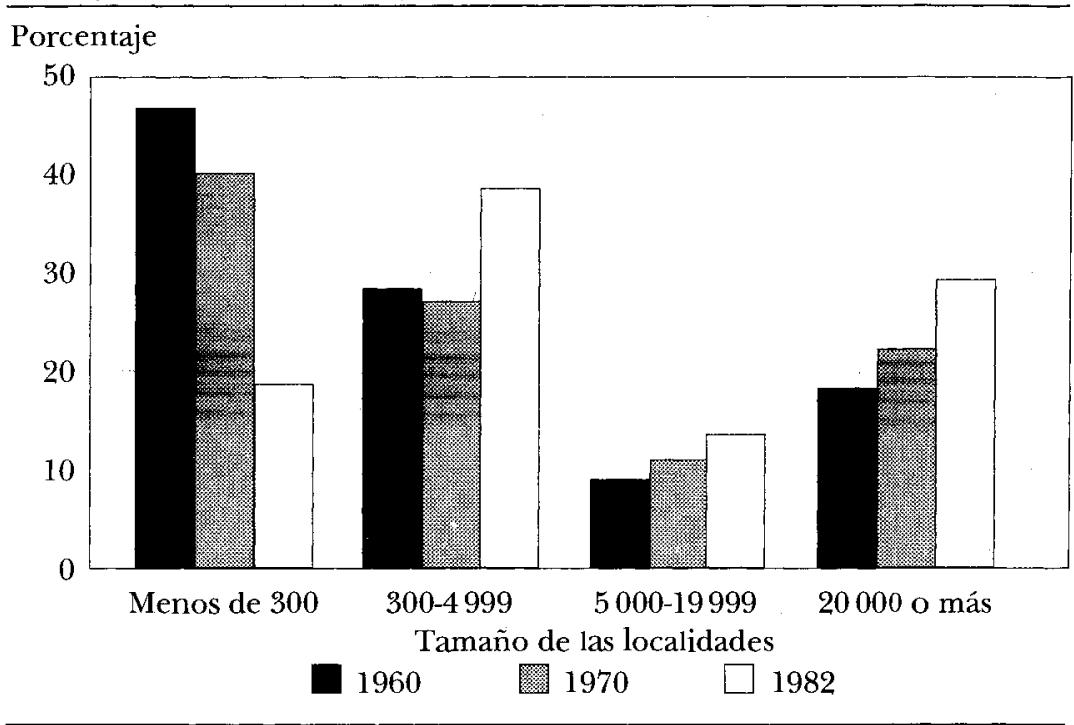

Fuente: INE, Censos de Población y Vivienda.

pal tipo de poblados en lo que se refiere a cantidad de población. Finalmente, aunque las localidades urbanas mantienen su nivel, ya no constituyen las de mayor peso en términos absolutos ni relativos.

Para establecer la magnitud de estos cambios en la distribución espacial de la población, hemos estimado los saldos netos migratorios por tipo de localidad según su tamaño (cuadro 2). Estos saldos nos dicen cuánto gana o pierde cada tipo de localidad, aunque nada nos dicen respecto del origen/destino de tales migraciones. ${ }^{7}$

${ }^{7}$ La estimación del saldo neto migratorio (sNM) por tipo de localidad se hizo del siguiente modo:

$$
\mathrm{sNM}=\mathrm{P}_{\mathrm{o}, \mathrm{t}}-\mathrm{P}_{\mathrm{e}, \mathrm{t}}
$$

Donde $\mathrm{P}_{\mathrm{o}, \mathrm{t}}$ es la población observada en el momento $t$ y $\mathrm{P}_{\mathrm{e}, \mathrm{t}}$ es la población es perada en el momento $t$, bajo el supuesto de ausencia de migración. Así, $\mathbf{P}_{\mathrm{e}, \mathrm{t}}$ se calcula del siguiente modo:

$$
P_{e, t}=P_{o, t-k} * e^{k * r}
$$

Donde $r=$ tasa de crecimiento natural. De esta forma, si $P_{o, t}>P_{e, t}$, entonces SNM $>0$, y si $\mathbf{P}_{\mathbf{o}, \mathrm{t}<} \mathbf{P}_{\mathrm{e}, \mathrm{t}}$, entonces SNM $<0$.

Para más detalles, véase Alejandro Canales, 1995: 421 y ss. 


\section{GUADRO 2}

VI Región, Chile. Saldos netos migratorios según el tamaño de las localidades. 1960-1970 y 1970-1982

\begin{tabular}{lccccc}
\hline \multirow{2}{*}{$\begin{array}{l}\text { Tamaño } \\
\text { delas }\end{array}$} & \multicolumn{2}{c}{ SNM total } & & \multicolumn{2}{c}{ Tasa anual $(0 / 00)$} \\
\cline { 2 - 3 } localidades & $1960-1970$ & $1970-1982$ & & $1960-1970$ & $1970-1982$ \\
\hline Total & -65903 & -24275 & -14.5 & -3.8 \\
20000 o más & 17854 & 27120 & 18.8 & 15.8 \\
$5000-19999$ & 3791 & 12173 & & 8.5 & 15.7 \\
$300-4999$ & -24097 & 65842 & & -20.2 & 31.6 \\
$0-299$ & -63451 & -129410 & & -32.6 & -70.8 \\
\hline
\end{tabular}

Fuente: Canales, 1995: 285, cuadro VII. 7.

En los sesenta, tanto las localidades rurales dispersas (menos de 300 habitantes) como las de 300 a 4999 habitantes eran expulsoras netas de población. En conjunto, ambas expulsaron alrededor de 87000 personas. Asimismo, las localidades urbanas de más de 20000 habitantes recibieron población, aunque en montos muy bajos (menos de 18000 ). Esto da cuenta de la alta emigración neta regional en esa década.

En los setenta en cambio, aunque se reduce significativamente la emigración neta regional (de 65000 emigrantes a menos de 25000 ), se observa sin embargo, un sustancial incremento en la emigración neta desde localidades dispersas (de menos de 300 habitantes), la que involucra a casi 130000 personas. Por su parte, las localidades de más de 20000 habitantes tienden a disminuir su fuerza de atracción demográfica, pasando de una tasa de inmigración neta de 19 por mil en los sesenta, a una de menos de 16 por mil en los setenta. Por el contrario, las localidades de 300 a 4999 habitantes, se constituyen en los setenta como las de mayor atracción neta de población con un saldo neto migratorio de 65000 personas. ${ }^{8}$

\footnotetext{
${ }^{8}$ Cabe señalar que el incremento de la población en localidades de 300 a 4999 habitantes, no corresponde a un simple cambio de clasificación de las localidades. En efecto, el número de localidades de este tipo apenas se incrementó $20 \%$ entre 1970 y 1982. En cambio, su población lo hizo más de $80 \%$. Esto hace que el tamaño promedio de estas localidades se haya incrementado $50 \%$ aproximadamente, pasando de 1060 habitantes en 1970 a 1508 habitantes en 1982. Este incremento en el tamaño medio es reflejo de un sustantivo flujo migratorio proveniente de localidades dispersas. Véase Alejandro Canales, 1995: 279 y ss.
} 
Estos datos ilustran el alto grado de movilidad intrarregional experimentado por la población en la década de los setenta, la que parece sustituir en monto e importancia relativa la anterior movilidad extrarregional de la población. Asimismo, este nuevo patrón de movilidad territorial de la población adquiere un carácter especial y diferente de la migración rural-urbana clásica, particularmente en términos de la relación migración-empleo. Esto lo podemos ilustrar con base en la información sobre la composición de la fuerza de trabajo por rama de actividad y su asociación con los cambios en la dinámica migratoria intra y extrarregional.

\section{Composición de la población económicamente activa}

En cuanto a la composición de la población económicamente activa (PEA) según rama de actividad, lo relevante parece ser la sustancial diferencia entre las tendencias que se observan en una y otra década. $\mathrm{Si}$ de 1960 a 1970 la tendencia principal fue la reducción de la PEA agrícola junto con un incremento de la PEA en los demás sectores, en los setenta en cambio, lo significativo es que la PEA agrícola frena su descenso, manteniéndose $43 \%$ de la PEA total. Asimismo, la PEA industrial desciende de $23.3 \%$ en 1970 a $19.6 \%$ en 1982 , mientras que la PEA en comercio y servicios incrementan su participación (cuadro 3).

CUADRO 3

VI Región, Chile. Población económicamente activa por rama de actividad, 1960,1970 y 1982

\begin{tabular}{|c|c|c|c|c|c|c|}
\hline \multirow{2}{*}{$\begin{array}{l}\text { Rama } \\
\text { de } \\
\text { actividad }\end{array}$} & \multicolumn{3}{|c|}{$P E A$} & \multicolumn{3}{|c|}{ Porcentajes } \\
\hline & 1960 & 1970 & 1982 & 1960 & 1970 & 1982 \\
\hline Total VI Región & 128637 & 136863 & 179752 & 100 & 100 & 100 \\
\hline Agricultura & 71901 & 61554 & 76846 & 55.9 & 45.0 & 42.8 \\
\hline Industria & 25055 & 31883 & 35172 & 19.5 & 23.3 & 19.6 \\
\hline Comercio & 12908 & 20440 & 32889 & 10.0 & 14.9 & 18.3 \\
\hline Servicios & 18773 & 22986 & 34845 & 14.6 & 16.8 & 19.4 \\
\hline
\end{tabular}

Fuente: INE, Censos de Población y Vivienda, 1960, 1970 y 1982. 
Ahora bien, si consideramos conjuntamente estas tendencias en la composición de la PEA con los cambios en la redistribución espacial de la población ya descritos, observaremos importantes asociaciones. En el cuadro 4 se presenta la composición de la PEA por sector de actividad, tan to para los municipios rurales como para los urbanos. De acuerdo con estos datos, los municipios rurales prácticamente no presentan mayores variaciones en la composición de su población activa, manteniéndose el predominio de las actividades agrícolas en las que participa alrededor de $70 \%$ de la PEA total. En este caso, la emigración rural no parece afectar la estructura de la PEA en las zonas de origen, tanto en los sesenta como en la década siguiente.

CUADRO 4

VI Región, Chile. PEA por sector de actividad y tipo de municipio

\begin{tabular}{lrrrrrrr}
\hline & \multicolumn{3}{c}{ Municipios rurales } & \multicolumn{3}{c}{ Municipios urbanos } \\
\cline { 2 - 4 } Rama de actividad & 1960 & 1970 & 1982 & 1960 & 1970 & 1982 \\
\hline Total & 100 & 100 & 100 & 100 & 100 & 100 \\
Agricultura & 73.0 & 71.1 & 69.0 & 37.1 & 27.3 & 32.5 \\
Industria & 9.0 & 8.7 & 9.7 & 30.8 & 33.2 & 23.4 \\
Comercio & 7.2 & 9.6 & 9.5 & 13.3 & 18.6 & 21.7 \\
Servicios & 10.9 & 10.6 & 11.8 & 18.8 & 21.0 & 22.4 \\
& & & & & & \\
\hline
\end{tabular}

Fuente: elaboración propia con base en Censos de Población y Vivienda.

En los municipios urbanos en cambio, sí se presentan variaciones importantes en la composición de la PEA de una década a otra. Si en los sesenta la PEA que residía en este tipo de municipio tendió a hacerse menos agrícola a la vez que más industrial, en los setenta en cambio, esta relación prácticamente se invierte. La PEA agrícola sube de $27 \%$ en 1970 a $33 \%$ en 1982 , mientras que la PEA industrial desciende su participación de $33 \%$ a $23 \%$ para esos mismos años. En este caso, la inmigración urbana sí tiene impactos diferenciados de una década a otra respecto de la composición de la PEA en los lugares de destino. Si en los sesenta el proceso de urbanización regional estuvo directamente asociado a una sustitución de actividades agrícolas por manufactureras, en los setenta, por el contrario, la redistribución espacial de la población desde el campo a las ciudades parece estar acompañada por un proceso de sustitución en sentido inverso, esto es, por el 
descenso de la PEA industrial y un incremento de la PEA agrícola que reside en zonas urbanas.

Esta reversión del proceso de sustitución de actividades agrícolas por manufactureras en áreas urbanas, en un contexto en que se ha intensificado la migración rural-urbana, ilustra uno de los principales cambios en la configuración regional de las relaciones campo-ciudad de una década a otra. Si hasta los sesenta la migración rural-urbana estuvo asociada a una movilidad de la fuerza de trabajo desde ocupaciones agrícolas a ocupaciones más típicamente urbanas, esto es, que la movilidad territorial estuvo asociada a una movilidad laboral caracterizada por un cambio ocupacional y sectorial, a partir de los setenta vemos que esta relación prácticamente desaparece presentándose una virtual disociación entre la movilidad territorial de la población y la movilidad ocupacional (sectorial) de la fuerza de trabajo. O lo que es lo mismo, que tal movilidad territorial de la población corresponde en definitiva al cambio de residencia (de hábitat rural a urbano) de gran parte de la fuerza de trabajo agrícola, lo que confiere significado y sentido particulares a las nuevas pautas de poblamiento en el ámbito regional.

Para entender la masividad y profundidad de estos cambios en la dinámica del empleo agrícola y el poblamiento rural, a continuación presentamos un breve análisis que vincula estas tendencias en el nivel empírico con una conceptualización de la dinámica de cada una de las fases y momentos del cambio agrario en Chile.

\section{Cambio agrario, empleo agrícola y poblamiento regional}

En la segunda mitad del presente siglo, podemos distinguir tres etapas claramente diferenciables en el desarrollo agrario chileno. Por un lado, el periodo de descomposición de la hacienda; en segundo lugar, el proceso de reforma agraria (1965-1973); y por último, la actual fase de expansión capitalista y reconversión agroexportadora. En cada una de estas fases se han generado condiciones particulares para un determinado tipo de desarrollo agrario, así como una particular articulación entre el patrón de poblamiento regional y el empleo agrícola.

\section{Descomposición del sistema de hacienda y poblamiento rural}

La hacienda chilena se remonta al siglo xVII, y constituyó desde entonces no sólo un sistema económico-productivo, sino también uno so- 
cial. Como señala José Bengoa, la hacienda representó una primera relación social fundante de la sociedad chilena, esto es, un primer sistema de poblamiento y de constitución social y política de Chile. ${ }^{9}$ Dentro de la hacienda se localizaban la iglesia, la escuela, las tiendas y en general un conjunto de servicios e instituciones sociales que permitían al hacendado controlar a sus inquilinos y trabajadores, y a la vez ampliar su influencia fuera de la hacienda llegando a monopolizar gran parte de los vínculos con la cultura, la sociedad y la política urbanas. ${ }^{10}$

Dentro de la hacienda, el inquilinato constituía la relación social básica; ésta consistía en una relación patrón-obrero de tipo semifeudal y precapitalista, según la cual el inquilino se obligaba a permanecer en la explotación proporcionando mano de obra a cambio de una vivienda para él y su familia, así como el usufructo de pequeñas extensiones de tierras en forma de "regalías productivas". Así pues, el inquilino cumplía un doble papel: "por un lado, era un productor que trabajaba una pequeña parcela de tierra por la cual pagaba una renta; y por otro, era un jornalero agrícola que prestaba sus servicios en las tierras del patrón" (Kay, 1980: 68).

Junto a los inquilinos, la hacienda disponía de otras categorías de trabajadores, tales como los peones obligados que eran familiares de los inquilinos y permitían cubrir aquella parte del arriendo que era pagada en forma de trabajo; los voluntarios, residían al interior de la hacienda pero no disponían de tierras en calidad de "regalías". También estaban los empleados quienes eran parte de la estructura administrativa; los afuerinos y los gañanes, trabajadores externos a la hacienda que provenían de predios campesinos circundantes a ella o de pueblos y villorrios cercanos. Unos y otros eran contratados en gran número, especialmente para el periodo de las cosechas (Ortega, 1987; Kay, 1980).

En este tipo de estructura agraria, la hacienda constituía el centro organizador del empleo así como del poblamiento rural en Chile. Si hasta el siglo xviı prevaleció una distribución más bien anárquica y desorganizada de las tenencias, ranchos y potreros de los inquilinos,

9 “... en el campo, en la agricultura, entendida como posesión y ocupación del suelo, se encuentra el origen histórico de la diferenciación social, la constitución del poder sustantivo o fundamental de la sociedad chilena. Allí reside la paradoja peculiar de este país. País urbano desde casi su inicio colonizado, minero en cuanto a su riqueza, y rural en su constitución". Bengoa, 1988: 15.

${ }^{10} \mathrm{Al}$ respecto véase Bauer y Hagerman Johnson, 1987. 
ya en el siglo xIx se dio una reorganización territorial de las haciendas, que implicó la relocalización de los ranchos campesinos a lo largo de alguno de los caminos radiales que existían adentro de aquéllas (Salazar, 1989). Esta pauta de poblamiento rural se extendió hasta mediados de este siglo conformando un patrón de asentamiento de la población de tipo disperso pero articulado económica y socialmente al poder central de las casas patronales. En este contexto, las relaciones de producción de tipo semifeudal (el inquilinato, entre otras) establecían un nexo entre el trabajador y la tierra que perduraría hasta principios de los sesenta aproximadamente. En términos del poblamiento rural, esto se expresa en una estrecha relación y asociación entre el lugar de residencia de la fuerza de trabajo agrícola y su lugar de empleo (Cruz, 1986).

No obstante, durante este siglo ese patrón de empleo y composición de la fuerza de trabajo fue paulatinamente cambiando y modernizándose. Por un lado, se incrementó la participación de los afuerinos y gañanes en contraposición de los trabajadores internos de las haciendas. Por otro lado, tendieron a disminuir las regalías y formas de pago en especies, aumentando la proporción que representaba el pago en dinero, acercándose gradualmente a lo que serían formas propiamente salariales (Szasz, 1994; Schejtman, 1971). Asimismo, a partir de los años treinta y con más fuerza en los cincuenta, el crecimiento demográfico, junto a la manutención de relaciones precapitalistas propias del sistema de hacienda, generaron una fuerte presión sobre la tierra que tendió a resolverse vía la emigración de este excedente poblacional hacia las grandes ciudades. ${ }^{11}$

\section{Reforma agraria y redistribución espacial de la población}

En los años sesenta se inicia el proceso de reforma agraria, que entre otros objetivos pretendía transformar y modernizar la estructura agraria

\footnotetext{
${ }^{11}$ Esta emigración rural sin embargo, no implicaba necesariamente una ruptura del orden social imperante en el agro hasta ese entonces. Por el contrario, esta emigración de campesinos hacia las grandes ciudades constituía más bien, una forma de disminuir la presión demográfica y social sobre una estructura agraria tradicional y arcaica que se oponía a su transformación y modernización. De hecho, tal "fuga" de inquilinos, minifundistas y población rural en general, no era sino la única respuesta que el orden agrario tradicional podía ofrecer a tal presión social, lo cual refleja a su vez lo anacrónico del sistema social imperante en el agro chileno al menos hasta principios de los años sesenta. Sobre este punto véase Bengoa, 1988; y Salazar, 1989.
} 
con el propósito de superar uno de los obstáculos que se presentaban para la expansión y consolidación del capitalismo en el agro, así como al proceso de industrialización sustitutiva de importaciones (Chonchol, 1970; Huerta, 1989).

El proceso de reforma agraria implicó la expropiación de cerca de 5800 predios agrícolas con alrededor de diez millones de hectáreas. De éstas, más de 700000 eran de riego, y casi tres millones de secano arable. Estas cifras representaban $40 \%$ de la superficie cultivable y $60 \%$ de la superficie de riego de todo el país (Cereceda y Dahse, 1980). Asimismo, durante la reforma agraria se dio un fuerte impulso a la organización del movimiento campesino, en la formación y legalización tanto de sindicatos de trabajadores agrícolas como de cooperativas de pequeños productores y a otras formas de organización del sector reformado. A su vez, el crédito y la asistencia técnica se hicieron extensivos a todos los productores agrícolas implantándose programas especiales para lograr la capitalización de los campesinos del sector reformado y los pequeños propietarios (Lehman, 1992).

Aunque la reforma agraria duró sólo ocho años (de 1965 a 1973), fue un proceso radical y profundo que llevó a la disolución de las viejas estructuras del agro, sustentadas en el sistema de hacienda. Por un lado, el inquilinato, que ya venía en declive, desapareció definitivamente del paisaje rural, dando paso a los beneficiarios de la reforma agraria (parceleros), así como a trabajadores asalariados permanentes y temporales. Por otro lado, y en paralelo a la creación de un área agrícola reformada, se formó un nuevo tipo de empresa agrícola que surgió, en unos casos, de predios de mediana extensión no susceptibles de expropiación y en otros, de divisiones privadas de los fundos ( $h i$ juelas) y de las reservas dejadas en propiedad de los exlatifundistas (Grupo de Investigaciones Agrarias, 1970). Junto a ellos, permanece el sector minifundista, que aunque estuvo lejos de ser el principal beneficiario de los distintos programas de apoyo crediticio, tecnológico y comercial, al menos dejó de ser un sector explotado por las haciendas a través del clásico complejo latifundio-minifundio.

En términos de las pautas de distribución espacial de la población, éstas no sufrieron grandes modificaciones. Aunque se construyeron algunos villorrios y asentamientos, la mayor parte de la población beneficiada continuó residiendo en las antiguas casas hacendales o en otras nuevas, pero que tendían a reproducir su posición y configuración en el espacio rural. 
No obstante, la reforma agraria genera un importante cambio en las condiciones de expulsión y retención de la población rural, que aunque no logra revertir la inercia de la migración rural-urbana y la fuerza de atracción demográfica de Santiago y otras áreas metropolitanas, sí permite disminuir la intensidad de la emigración rural. En el caso de la VI Región, por ejemplo, en los sesenta se dio una importante reducción de la emigración, especialmente en aquellas zonas y municipios donde el proceso de reforma agraria fue más intenso y radical. A ello parecen haber contribuido factores como el reparto de tierras, la mayor participación e involucramiento de los trabajadores agrícolas con la organización de la producción, y el mejoramiento de las condiciones de vida de la población rural, entre otros (Argüello, 1975).

En síntesis, de lo anteriormente expuesto podemos concluir que tanto en el sistema hacendal como en el corto periodo de la reforma agraria, existió una estrecha relación entre el lugar de residencia de la mano de obra agrícola y su lugar de trabajo. La excepción puede ser la precursora tendencia que se perfiló en las empresas agrícolas más modernizadas, así como la presencia, desde décadas atrás, de los pueblos rurales. Interesa resaltar este punto pues será precisamente tal relación entre lugar de residencia y empleo la que tenderá a quebrarse y desarticularse definitivamente con el modelo agroexportador. ${ }^{12}$

\section{Modelo agroexportador y poblamiento regional}

El nuevo modelo económico impulsado por los militares implicó, en lo externo, la reinserción de Chile en el mercado internacional basada en la política de promoción de exportaciones no tradicionales (silvoagropecuarias, en particular). ${ }^{13}$ Asimismo, en lo interno, implicó una profunda restructuración del sistema económico productivo donde el centro de la acumulación y el crecimiento se trasladaron

12 Según María Elena Cruz (1986), pareciera ser que la tendencia a desvincular el lugar de residencia del lugar de trabajo, que se manifiesta nítidamente en la década de los setenta con la expulsión de población desde los campos, ya estaba presente en modo latente en el sector de las empresas comerciales, pero que no se expresaba básicamente por la fuerza de los sindicatos agrícolas así como por las formas y carácter de la intervención del Estado.

${ }^{19}$ En Chile, desde el siglo pasado la base exportadora ha estado conformada por el sector minero: el carbón y el salitre en el siglo xix, y el cobre en este siglo. De ahí que suele hablarse de "exportaciones no tradicionales" para referirse a las exportaciones no mineras, y no cupríferas en particular. 
desde el sector urbano-industrial hacia aquellas regiones y sectores productivos que gozaban de ciertas ventajas comparativas en el comercio in ternacional; en particular, el sector agroexportador (Geisse, 1983; Boisier, 1990).

En lo que respecta al modelo agrario del proyecto neoliberal, éste ha tenido un fuerte carácter diferenciador en función de la desigual distribución de las ventajas comparativas a lo largo del país. Así, mientras las regiones agroexportadoras (Valle Central y Región Costera del Centro-Sur) han mostrado un comportamiento dinámico, de alta capitalización y especialización productiva, las regiones del sur en cambio, productoras de alimentos para el consumo interno, han experimentado el proceso opuesto (Bengoa et al., 1979). Esta expansión capitalista en zonas agroexportadoras ha permitido activar un proceso de modernización del agro chileno que podemos sintetizar fundamentalmente en tres aspectos:

- La desarticulación del área reformada. Este proceso se llevó a cabo mediante la llamada "regularización de la tenencia de la tierra", que consistió en la reprivatización de los predios expropiados durante la reforma agraria. Como parte de este proceso, entre septiembre de 1973 y febrero de 1979 habían entrado en proceso de regularización más de $90 \%$ de los predios expropiados, con un total de 895000 hectáreas de riego básico (HRB)..$^{14} 52 \%$ de estas tierras se subdividieron en más de 46000 predios, los que fueron asignados a familias campesinas en forma de parcelas individuales, con una extensión promedio de diez HRB cada una. Esta política de reparto, sin embargo, sólo se restringió a la tierra y no incluyó al capital ni a la infraestructura agraria. Además, el sistema de créditos y los circuitos de comercialización se privatizaron dejando al margen a amplios sectores campesinos.

Otro $20 \%$ de la superficie se transfirió al sector privado por medio de ventas y licitaciones directas, mientras que $28 \%$ de la superficie fue devuelta a sus antiguos dueños, pero en predios con una extensión significativamente menor a la que les fue expropiada (Jarvis, 1992). Este proceso de privatización tenía como propósito fortalecer la mediana explotación agrícola, que se consideraba como la base para el proceso de modernización del agro que se deseaba impulsar.

\footnotetext{
${ }^{14}$ Cereceda y Dahse, 1980. La hectárea de riego básico es una unidad de medida construida técnicamente que permite hacer equivalencias entre suelos de distinta calidad y de diferentes condiciones geoeconómicas (presencia de sistemas de regadío, acceso a mercados, tipos de suelos, etcétera).
} 
Sin embargo, este proceso de regularización y reprivatización de la propiedad agrícola dejó al margen del reparto de tierras a más de $50 \%$ de los campesinos que habían participado en el proceso de reforma agraria, a los que se suma otro $25 \%$ de campesinos que se vieron en la necesidad de vender o subarrendar sus parcelas individuales agobiados por las altas deudas y precarias condiciones de sobrevivencia. Este sector de campesinos entró en proceso de proletarización, engrosando las filas del proletariado rural, empleándose temporalmente en actividades agrícolas y pasando gran parte del año desempleado o subempleado en diversas actividades (Rivera y Cruz, 1984).

- Reconversión agroproductiva. Este proceso se sustenta en dos dinámicas fundamentales: la reorientación de la producción hacia cultivos de exportación en desmedro de los cultivos tradicionales y de consumo interno, por un lado; y la modernización y tecnificación de los procesos productivos, por otro (Martner, 1989 y Ortega, 1987).

La reorientación de la agricultura chilena hacia mercados de exportación, implicó un cambio radical en la estructura de uso del suelo agrícola. Entre 1975 y 1985, por ejemplo, la superficie destinada a cultivos básicos (chacras, cereales, cultivos industriales tradicionales, etc.) disminuyó en casi 20\%, mientras que la superficie destinada a plantaciones forestales, por un lado, y por otro, a parronales y frutales, se incrementaron 53 y $72 \%$, respectivamente (Instituto Nacional de Estadística, 1987).

Asimismo, la introducción y difusión de paquetes tecnológicos modernos (revolución verde, biotecnología, etc.) es más o menos reciente en el agro chileno. Si bien en los sesenta, y gracias a la reforma agraria, se dio una primera introducción de nuevas tecnologías (semillas mejoradas, mecanización, etc.) que implicaron un incremento en los rendimientos en ciertos productos (cereales, chacras y algunos cultivos industriales), es en los años ochenta cuando su difusión adquiere cierta masividad, alterando significativamente los sistemas tecno-productivos agrarios, especialmente en lo que se refiere al nivel de los rendimientos y el uso de semillas mejoradas e insumos químicos.

- Empleo temporal y "feminización" del mercado de trabajo agricola. Un aspecto central del actual modelo agrario, se refiere a los cambios en el patrón de empleo, el que de ser mayoritariamente permanente, ha pasado a su forma actual de extrema temporalidad y precariedad. Esta sustitución del trabajo permanente por el de tipo temporal parece asociarse a los cambios en el uso del suelo agrícola; en particular, a la sustitución de cultivos de ciclo corto (menos de un año) por aquéllos 
de ciclo largo - frutales, parronales y/o forestales- (Gómez y Echenique, 1988; Crispi y Rivera, 1984). Asimismo, esta mayor estacionalidad del empleo agrícola resulta ser más intensa en aquellas regiones de actividad agroexportadora; los cultivos exportables muestran la mayor variación en la demanda de trabajo entre los meses de máxima (cosecha, verano) y de mínima (invierno) (Ortega, 1987).

$\mathrm{Al}$ respecto, P. García (1985), refiriéndose a la VI Región, señala que al pasarse de una situación de policultivos en rotación, prevaleciente hasta principios de los setenta, a una especialización frutícola que domina en la actualidad, los requerimientos en el trimestre de menos demanda conducen a retener en la explotación sólo a la quinta parte de la demanda total de mano de obra.

Junto a este carácter temporal, aparece la feminización del mercado de trabajo agrícola como resultado de la creciente incorporación de la mujer al trabajo agrícola asalariado (y de temporada). En la fruticultura por ejemplo, a fines de los ochenta más de la mitad de los trabajadores eran mujeres y el número de trabajadoras temporeras superaba al total de obreras de la manufactura (Venegas L., 1995). Esta importante presencia femenina en la fruticultura, deviene en una clara división sexual del trabajo, en la medida que se genera una demanda de trabajo diferenciada para hombres y mujeres. En efecto, "mientras que sólo los hombres logran incorporarse al mercado de trabajo frutícola permanente, hombres y mujeres constituyen el elemento esencial de la fuerza de trabajo contratada por temporadas para las labores estacionales de la fruticultura" (Valdés, 1992: 98-99).

Ambos aspectos (empleo temporal y feminización) forman parte del nuevo contexto sociolaboral del agro chileno, que se caracteriza además por el alto grado de flexibilización y desregulación en las relaciones laborales y contractuales, características intrinsecas del actual funcionamiento del mercado laboral agrícola, y componente esencial del nuevo modelo de desarrollo. ${ }^{15}$

En relación con las pautas del poblamiento regional y rural, el impacto más importante de la modernización capitalista del agro chileno ha sido la expulsión masiva de trabajadores permanentes desde sus antiguos lugares de residencia y empleo hacia poblaciones marginales situadas en espacios rurales, o en poblados y ciudades interme-

${ }^{15}$ Un ejemplo de ello se refiere a la prohibición legal de sindicatos de trabajadores tem poreros, así como de cualquier forma de negociación colectiva de los contratos laborales, prestaciones sociales y condiciones de trabajo. Al respecto, véase Silva, 1992. 
dias, pero localizadas en zonas de actividad predominantemente agrícola. ${ }^{16}$ Estos cambios implican, a nuestro entender, un doble proceso en cuanto a la dinámica del poblamiento rural, a saber:

- Por un lado, se genera un desarraigo, esto es, expulsión de población desde sus campos, en la medida que las tierras que les fueron entregadas durante la Reforma Agraria son ahora requeridas para los cultivos de exportación. Así, se sustituye la producción campesina y la del ex-hacendado, por producción comercial y capitalista, así como el trabajo del campesino, de los antiguos inquilinos y demás trabajadores agrícolas, por el de trabajadores foráneos temporales asalariados.

- Sin embargo, ese desarraigo es sólo parcial. Es un desarraigo en lo referente al hábitat, al ámbito de residencia y al momento reproductivo, pero no lo es en cuanto a la fuente de empleo; al momento productivo, propiamente. Todo ello redunda en la configuración de una nueva forma de arraigo establecida no ya por medio de relaciones sociales precapitalistas (inquilinato), ni extraeconómicas (paternalismo, clientelismo), sino mediante relaciones estrictamente económicas reguladas por la dinámica del mercado laboral. ${ }^{17}$

En términos de la reproducción social de la fuerza de trabajo, esta disociación la podemos definir como separación espacial entre los tiempos de trabajo y los de reproducción. Es decir, mientras en el pasado el sistema de relaciones sociales de producción (inquilinato) imponía que en un mismo espacio social (la hacienda) se conjugaran los tiempos de trabajo y de reproducción, en la actual época de expansión capitalista, la proletarización de la fuerza de trabajo agrícola rompe esta relación disociando social y espacialmente estos distintos tiempos de la producción y reproducción social de la fuerza de trabajo agrícola.

En otras palabras, en la hacienda, ni para el inquilino ni para el hacendado había forma de separar espacialmente los diferentes tiempos

${ }^{16}$ En el caso de la VI Región, por ejemplo, en los setenta esta emigración masiva de población desde el campo involucró a más de 129 mil personas, cifra que representa más de $50 \%$ de la población rural. Véase cuadro 2.

${ }^{17}$ Claro está sin embargo, que esta dinámica del mercado laboral está signada por el carácter desigual y asimétrico de las relaciones laborales entre trabajadores y patrones, que dice regular. Esto es, la precarización de las condiciones de vida y reproducción de los trabajadores, la temporalidad del empleo agrícola, junto a la flexibilización de los contratos laborales (cuando existen) y a la inexistencia legal de sindicatos de trabajadores temporeros, son factores no económicos, que junto a otros, inciden directamente en la regulación de la dinámica del mercado laboral, y que los teóricos del neoliberalismo en Chile, han denominado como proceso de desregulación y liberalización del mercado laboral y de la economía en su conjunto. 
(productivos y reproductivos) ni inversamente, disociar temporalmente los espacios de la producción de los de la reproducción. De hecho, en ambos espacios y en ambos tiempos, regían por igual las relaciones de servilismo y paternalismo que caracterizaban el sistema de inquilinato. Por el contrario, con la modernización del agro basada en un esquema neoliberal y de exclusión social, el desarraigo en realidad corresponde a la separación de los espacios y tiempos productivos de los reproductivos. Así, hay un espacio específico y un tiempo definido para cada proceso, mismos que no se ven mezclados ni integrados. ${ }^{18}$

Esta disociación constituye un punto central en la actual dinámica del poblamiento regional. Es un componente básico y fundamental que nos permite una mejor comprensión de la profundidad de los cambios operados en el agro bajo el modelo agroexportador. En tal sentido, esta disociación, este desarraigo, nos permite sustentar algunas reflexiones finales sobre la situación actual del agro en Chile, en particular, sobre la forma en que se conjugan los éxitos económicos con los fracasos sociales en la aplicación del modelo económico neoliberal.

\section{Reflexiones finales}

El análisis de las diferentes fases del proceso de cambio agrario en Chile, nos permite concluir que los cambios en el poblamiento y uso del espacio rural y regional, han estado íntimamente asociados a los cambios en las formas de existencia y reproducción social de la fuerza de trabajo, y por ese medio, a las distintas fases del desarrollo del capitalismo en el agro chileno. La sustitución del inquilino por el trabajador asalariado (básicamente el temporero), y el paso de la hacienda a la empresa agrícola (y por ende del hacendado al empresario capitalista) han implicado una masiva expulsión de población desde los campos, la que, sin embargo, no tiende a ser absorbida por las grandes ciudades.

${ }^{18}$ De hecho, lo único que permite vincular cada uno de estos ámbitos espaciotemporales, es precisamente la acción "libre" de los mercados, mecanismo mediante el cual se "conectan" los distintos agentes económicos y se "resuelven" las diferentes demandas que se generan en cada ámbito espacio-temporal. En este sentido, la subordinación que caracterizaba a las relaciones patrón-inquilino en la hacienda no desaparece, sino que es trasladada al mercado bajo la forma de una asimetría de poder en la regulación de las relaciones capital-trabajo. 
Asimismo, dadas las condiciones de desarrollo nacional imperantes a partir de 1974, las zonas metropolitanas se han caracterizado por su alto nivel de desempleo y el empeoramiento de las condiciones de vida de la población. En este contexto, la población rural expulsada del campo, ya no se dirige igual que antes a tales áreas urbanas, sino que tiende a relocalizarse en pequeños poblados o en la periferia de las pequeñas y medianas ciudades, pero sin que ello implique romper sus vínculos con las actividades agrícolas. ${ }^{19}$

Esta población constituye un nuevo y emergente sector social (los pobladores rurales) que en realidad emergen como una nueva forma de marginalidad y de pobreza. Es decir, así como en las décadas de los treinta a los sesenta la población expulsada de los campos se dirigía mayoritariamente hacia Santiago, participando así en la reproducción ampliada de la pobreza y marginalidad urbana, hoy en día, dadas las características del proceso global de desarrollo, ${ }^{20}$ esta población tiende a localizarse en poblados rurales o ciudades medias, participando así en la emergencia de una "nueva" forma de marginalidad y pobreza, ya no urbana sino rural y regional.

Esta nueva realidad - los poblados rurales-y sus características básicas (pobreza y marginalidad rural) junto con las características de las transformaciones estructurales, conforman un nuevo tipo de organización del espacio rural y regional. Esto nos permite hablar de nuevas pautas de ruralización y de configuración regional de la relación campo-ciudad, de una nueva ruralidad, caracterizada no sólo por la profundización de la desigualdad social (y espacial) sino también porque ella se da con base en la "modernización" de las estructuras económicas y productivas.

Ahora bien, con base en lo anterior, podemos proponer una relectura de la historia reciente del agro chileno, reinterpretándola como la historia del quiebre de la hacienda en tanto eje central sobre el que se construía una determinada forma de organización del agro y

${ }^{19}$ Estos nuevos procesos poblacionales, sin embargo, no son homogéneos a lo largo del país, sino que están condicionados por las desigualdades regionales que el nuevo patrón de acumulación ha profundizado. En este sentido, las tendencias señaladas sobre las nuevas pautas del poblamiento se expresan más nítidamente en aquellas regiones en donde el auge agroexportador ha sido el motor del dinamismo regional. Véase Rivera y Cruz, 1984.

${ }^{20}$ En particular, la reconversión industrial, el papel subsidiario del Estado, la desregulación de la economía, la desarticulación de organizaciones sindicales y populares, la flexibilización de contratos laborales, la precarización del empleo, etc. Sobre estos procesos de cambio en la economía chilena, véase García, Rivera y Vega, 1994. 
de lo rural, así como de sus vínculos con lo urbano y lo nacional. Junto a este quiebre se construye un nuevo orden social agrario que establece a su vez nuevas formas de estructuración espacial de las relaciones sociales.

Esta modernización del orden social agrario ha implicado, no obstante, la configuración de un contexto social marcado por la pauperización y precarización de las condiciones de vida y reproducción social de gran parte de la población rural y de la fuerza de trabajo agrícola (Ortega y Tironi, 1988). De esta forma, los poblados rurales y rur-urbanos, así como las ciudades medias y pequeñas, todos ellos receptores del creciente flujo de población que ha sido expulsada del campo, conforman hoy en día, el contexto socioespacial en el que se configura una versión renovada y "moderna" de lo que en el pasado constituyó la pobreza rural. Nos referimos a la condición de pobreza y marginación social que surge "del proceso mismo de modernización y crecimiento de la economía rural", que por lo mismo, "difiere significativamente de la pobreza tradicional, en cuanto sucede y acompaña a un proceso de modernización y crecimiento sostenido del sector agrícola" (Canales, González y Alderete, 1994: 11).

Si en un pasado más o menos reciente (antes de los sesenta) los inquilinos, minifundistas y demás trabajadores del campo, por su condición de exclusión social fueron caracterizados como los parias del modelo de industrialización (Bengoa, 1982), los más pobres entre los pobres y sobre quienes recayó un largo tiempo de olvido, silencio y marginación, hoy en día, la reconversión y modernización del agro chileno ha orillado a sus hijos y nietos a vivir una situación de abandono y exclusión socio-económica de características similares. Asimismo, si sobre los inquilinos y minifundistas recayó en el pasado la mayor carga del costo social de la industrialización sustitutiva en Chile, hoy en día es sobre sus descendientes en quienes ha vuelto a recaer la gran deuda social generada por la reconversión productiva y la modernización de la estructura agraria de Chile.

Así, esta relectura de la trayectoria del agro chileno en las últimas décadas tiene, como toda lectura de la historia, al menos dos miradas distintas y complementarias. Por un lado, una mirada desde su éxito, desde los logros de la modernización y el progreso económico, pero también una mirada desde la exclusión, desde los olvidados y silenciados por el arrollador y arrogante paso de dicha modernización.

La ironía que nos devela esta doble mirada de nuestra historia reciente, es que si en el pasado la pobreza rural fue vista como un rema- 
nente de estructuras sociales arcaicas que, como la hacienda, habían quedado ajenas al proceso de modernización (urbanización e industrialización), hoy en día en cambio, esta recreación de la pobreza en ámbitos urbano-regionales está directamente vinculada al proceso de modernización agrorregional. Esto es, si en el pasado la modernización y el progreso social que acompañaron a la industrialización en zonas urbanas no lograron romper con las estructuras sociales que determinaban las condiciones de generación y recreación de la pobreza rural, ahora, en cambio, es la propia dinámica de la modernización agrícola la que genera y produce sus propias formas de pobreza. Se trata de las condiciones de pobreza de una población inserta en zonas de alta modernización y crecimiento económico, de pobres plenamente integrados a un mercado laboral plenamente modernizado.

\section{Bibliografía}

Argüello, Omar (1975), Reforma agraria, participación y migraciones, Santiago de Chile, Programa Escuela Latinoamericana de Sociología, Flacso/Celade.

Bauer, Arnold y Ann Hagerman Johnson (1987), "Tierra y trabajo en el campo chileno, 1850-1935", en Kenneth Duncan e Iván Rutledge (comps.), La tierra y la mano de obra en América Latina. Ensayos sobre el desarrollo del ca pitalismo agrario en los siglos $x I x$ y $x x$, México, Fondo de Cultura Económica, pp. 98-119.

Bengoa, José (1988), El poder y la subordinación. Acerca del origen mural del poder.y la subordinación en Chile, Santiago de Chile, Ediciones Sur (Estudios Históricos).

(1982), "Trayectoria del campesinado chileno", documento de trabajo núm. 8, Santiago de Chile, Grupo de Investigaciones Agrarias, Academia de Humanismo Cristiano.

- _ et al. (1979), Capitalismo y campesinado en el agro chileno. Santiago de Chile, Grupo de Investigaciones Agrarias, Academia de Humanismo Cristiano (Serie Resultados de Investigación, 1).

Boisier, Sergio (1990), Territorio, estado y sociedad. Reflexiones sobre descentralización y desarrollo regional en Chile, Chile, Centro de Estudios de Asistencia Legislativa, Universidad Católica de Valparaíso.

Canales, Alejandro (1995), "Cambio agrario y poblamiento regional en Chile, 1952-1986. El caso de la VI región", tesis de doctorado, México, El Colegio de México.

Canales, Manuel, Daniel González y Francisco Alderete (1994), "Pobreza y desarrollo rural", documento de trabajo núm. 1, Santiago de Chile, Facultad de Ciencias Sociales, Universidad de Chile. 
Cereceda, Luz y Fernando Dahse (1980), Dos décadas de cambio en el agro chileno, Santiago de Chile, Instituto de Sociología, Pontificia Universidad Católica de Chile.

Chonchol, Jacques (1970), "Poder y reforma agraria en la experiencia chilena", en Chile hoy, México, Siglo XXI, pp. 255-321.

Crispi, Jaime (1980), "El agro chileno después de 1973: expansión capitalista y campesinización pauperizante", documento de trabajo 1, Santiago de Chile, Grupo de Investigaciones Agrarias, Academia de Humanismo Cristiano.

(1980), Agro, estado, clases sociales y acumulación en Chile. Un recuento his tórico, Santiago de Chile, Grupo de Investigaciones Agrarias, Academia de Humanismo Cristiano.

— y Rigoberto Rivera (1984), "Modernización y empleo rural" en Conceptualización del empleo mural con propósitos de medición, México, Secretaría del Trabajo y Previsión Social, oIT/PREALC.

Cruz, María Elena (1986), De inquilinos a temporeros, de la hacienda al poblado mu ral, documento de trabajo, núm. 21, Santiago de Chile, Grupo de Investigaciones Agrarias, Academia de Humanismo Cristiano.

Filippo, Armando di y Rosa Bravo (1977), Los centros nacionales de desarrollo y las migraciones internas en América Latina: un estudio de casos, Chile, documento de trabajo, núm. 16, Santiago de Chile, PISPAL.

García, Ligia, Eugenio Rivera y Juan Enrique Vega (1994), "Chile: posibilidades y riesgos de una integración activa en el mercado mundial”, en Cambio de rumbo en el cono sur: crisis y oportunidades, Venezuela, Nueva Sociedad.

García, Pío (1985), "El desarrollo frutícola en Chile y sus transformaciones sociales", Estudios e informes de la Cepal, núm. 57, Santiago de Chile.

Carretón, Manuel Antonio (1983), El proceso político chileno, Santiago de Chile, Flacso.

Geisse, Guillermo (1983), Economia y politica de la urbanización en Chile, México, El Colegio de México/PISPAL.

Gómez, Sergio y Jorge Echeñique (1988), La agricultura chilena: las dos caras de la modernización, Santiago de Chile, Flacso/agraria.

- y Jorge Echeñique (1988), Trabajadores temporeros de la agricultura moderna del Chile Central, documento de trabajo, núm. 324, Santiago de Chile, Flacso.

Grupo de Investigaciones Agrarias (1979), La tenencia de la tierra en Chile, Santiago de Chile, Grupo de Investigaciones Agrarias, Academia de Humanismo Cristiano (Cuadernillos de Información Agraria, 1).

Huerta, María Antonieta (1989), Otro agro para Chile. Historia de la reforma agraria en el proceso social y político, Santiago de Chile, Cesoc, Cisec.

Instituto Nacional de Estadística (1987), Compendio estadistico, Santiago de Chile.

Jarvis, Lovell (1992), "The Unravelling of the Agrarian Reform", en Cristóbal 
Kay y Patricio Silva (eds.), Development and Social Change in the Chilean Countryside. From the Pre-Land Reform Period to the Democratic Transition, Amsterdam, Centrum voor Studie en Documentatie van Latijns Amerika (CEDIA), pp. 189-213.

Kay, Cristóbal (1980), El sistema señorial europeo y la hacienda latinoamericana, México, ERA.

Lehmann, David (1992), "Political Incorporation versus Political Stability", en Cristóbal Kay y Patricio Silva (eds.), Development and Social Change in the Chilean Countryside. From the Pre-Land Reform Period to the Democratic Transition, Amsterdam, Centrum voor Studie en Documentatie van Latijns Amerika, pp. 111-127.

Martner, Gonzalo (1989), El hambre en Chile. Un estudio de la economía agroalimentaria nacional, Santiago de Chile, Grupo de Investigaciones Agrarias/United Nations Research Institute for Social Development.

Ortega, Emiliano (1987), Transformaciones agrarias y campesinado. De la participación a la exclusión, Santiago de Chile, Cieplan.

Ortega, Eugenio y Ernesto Tironi (1988), Pobreza en Chile, Santiago de Chile, Centro de Estudios del Desarrollo.

Rivera, Rigoberto y María Elena Cruz (1984), Pobladores rurales, Santiago de Chile, Grupo de Investigaciones Agrarias, Academia de Humanismo Cristiano (Serie Libros, 1).

Salazar, Gabriel (1989), Labradores, peones y proletarios. Formación y crisis de la sociedad popular chilena del siglo xix, Santiago de Chile, Ediciones SUR (Estudios Históricos).

Schejtman, Alexander (1971), El inquilino de Chile central, Santiago de Chile, Instituto de Capacitación e Investigación en Reforma Agraria, Gobierno de Chile.

Silva, Patricio (1992), "The State, Politics and Peasant Unions", en Cristóbal Kay y Patricio Silva (eds.), Development and Social Change in the Chilean Countryside. From the Pre-Land Reform Period to the Democratic Transition, Amsterdam, Centrum voor Studie en Documentatie van Latijns Amerika, pp. 215-232.

Szasz, Ivonne (1994), Mujeres inmigrantes y mercado de trabajo en Santiago, Serie E, núm. 39, Santiago de Chile, Celade.

Valdés, Ximena (1992), Mujer, trabajo y medio ambiente. Los nudos de la modernización agraria, Santiago de Chile, Centro de Estudios para el Desarrollo de la Mujer.

Venegas L., Sylvia (1995), "Las temporeras de la fruta en Chile", en X. Valdés et al. (eds.), Mujeres. Relaciones de género en la agricultura, Santiago de Chile, Centro de Estudios para el Desarrollo de la Mujer, pp. 119-155. 